\title{
O Microscópio como Objeto Escolar da Disciplina Biologia no Colégio Pedro II (1960-1970)
}

\author{
The Microscope as a School Object in Biology Lessons \\ at Pedro II High School (1960-1970)
}

ID Flaviana Alves de Oliveira' ${ }^{1}$
iD Maria Margarida Pereira de Lima Gomes ${ }^{1}$

'Universidade Federal do Rio de Janeiro (UFRJ), Centro de Filosofia e Ciências Humanas, Faculdade de Educação, Rio de Janeiro, RJ, Brasil.

Autora Correspondente: margaridagomes@ufrj.br

Resumo: Este trabalho apresenta como foco destrinchar os significados curriculares do microscópio no contexto do ensino de Biologia no Colégio Pedro II nos anos 1960/1970. Por meio de referenciais teóricos advindos da história das disciplinas escolares, da cultura material escolar e da antropologia, compreendemos que tal artefato produziu práticas culturais e curriculares que são parte da consolidação socio-histórica da disciplina Biologia na referida instituição. O microscópio é assim percebido como essencial na materialização das atividades práticas em associação com o que se considera o bom professor. O microscópio é ainda entendido como ponto central da ação docente, demarcando a sua respectiva comunidade disciplinar em torno de aulas práticas experimentais. Tal objeto é percebido como contribuinte para o processo de unificação, legitimação e modernização da Biologia escolar. Apesar de ele ter adicionado novos elementos ao seu fazer disciplinar, também conversou com tradições já consolidadas no âmbito da referida disciplina, relacionadas às práticas de dissecção de animais.

Palavras-chave: Ensino de biologia; Microscópio; Material didático; Equipamentos de laboratório.

Abstract: The study focuses on the curricular meanings of the microscope in the context of teaching Biology at Colégio Pedro II in the 1960s and 70s. Through theoretical references derived from the history of school subjects, school material culture and anthropology, we understand that such an artifact has produced cultural and curricular practices that are part of the socio-historical consolidation of Biology in that institution. The microscope is thus perceived as essential in the materialization of practical activities in association with what is considered the good teacher. The microscope is still understood as a central point in teaching actions, demarcating its respective disciplinary community around practical experimental classes. Such an object is perceived as a contributor to the process of unification, legitimation and modernization of biology in the school. Although it has added new elements to his disciplinary practice, it also interacted with traditions already consolidated within the scope of that discipline, with regard to animal dissection practices.

Keywords: Biology teaching; Microscope; Teaching materials; Laboratory equipment.

Recebido em: $07 / 04 / 2020$

Aprovado em: 07/06/2020 


\section{Introdução}

O presente trabalho apresenta como foco destrinchar os significados curriculares do microscópio no contexto da constituição do ensino de Biologia no Colégio Pedro II, buscando compreender como tal objeto escolar influenciou a consolidação da disciplina escolar Biologia no âmbito das aulas práticas de laboratório do gabinete de História Natural da referida instituição no período dos anos 1960-1970. Os resultados encontrados e as reflexões aqui desenvolvidas fazem parte de uma pesquisa, em nível de Mestrado (OLIVEIRA, 2018), que buscou desvendar como os objetos escolares conformavam o currículo de Biologia por meio de práticas, percebidas aqui como curriculares e culturais. A questão como o microscópio colaborou para a consolidação da disciplina escolar Biologia no Colégio Pedro II? orienta, portanto, as discussões aqui empreendidas. Para respondê-la, buscamos analisar tanto as políticas educacionais como as mudanças curriculares do ensino de Biologia no período em questão, com o objetivo de traçar seu panorama global em correlação com a história do microscópio na pesquisa científica e suas possíveis influências na Biologia escolar dessa instituição.

No intuito de apreendermos de que maneira o microscópio foi vetor de uma rede de relações no processo de transição disciplinar da História Natural para Biologia na instituição pesquisada, precisamos, em um primeiro momento, explicar conceitualmente a noção de objeto escolar. A pesquisadora Fiscarellli (2009) nos apresenta uma visão pertinente de objeto escolar como aquele que o docente "[...] possa utilizar em sala de aula, de maneira a interferir no processo de ensino e aprendizagem" (FISCARELLI, 2009, p. 11)'.

De maneira a complementar e enriquecer tal caracterização, buscamos compreender o microscópio enquanto objeto escolar, também a partir dos estudos da cultura material, que apresenta como expoente o pesquisador Escolano Benito (2010), que tem contribuído de forma expressiva para as investigações referentes ao papel da materialidade na análise das práticas pretéritas escolares. Por esse viés, os artefatos escolares são encarados como "restos arqueológicos" que nos informam sobre os fazeres internos escolares, seus valores e tradições, nos permitindo assim adentrar a sua "caixa preta" (ESCOLANO BENITO, 2010). Além disso, as próprias práticas docentes também são escrutinadas por meio do entendimento da relação entre o professor e a mobilização de materiais didáticos nas atividades escolares, contribuindo para a apreensão de como as disciplinas escolares são gestadas sócio-historicamente.

O campo da Antropologia também alargou os modos pelos quais os artefatos escolares foram percebidos na sua interface com a cultura escolar e, mais especificamente, com a cultura disciplinar da Biologia escolar. Miller (2013), antropólogo reconhecido pelos seus estudos em cultura material, em seu livro Trecos, troços e coisas: estudos antropológicos sobre cultura material, apresenta a teoria da humildade das coisas, expandindo o nosso olhar sobre os objetos como informantes e moduladores sobre modos de comportamento e normas sociais de maneira silenciosa. De modo simplificado, os objetos, como molduras e cenários, "formam as pessoas" (MILLER, 2013, p. 83). Resgatados tanto pela influência

\footnotetext{
${ }^{1}$ Embora essa definição e classificação constituem-se um desafio para o campo dos estudos da cultura material, de acordo com a abordagem teórica deste trabalho, o termo 'objeto' pode ser referenciado no campo educacional por uma multiplicidade de designações, tais como 'artefatos' e 'materiais didáticos'. Sendo assim, utilizamos tais expressões como sinônimos de objetos.
} 
em nossa subjetividade como pela sua "relevância social e simbólica" (GONÇALVES, 2007, p. 14), os artefatos escolares acabam nos inventando, "[...] uma vez que eles materializam uma teia de categorias de pensamento por meio das quais nos percebemos individual e coletivamente" (GONÇALVES, 2007, p. 29). Por meio dessa perspectiva, podemos inferir que a materialidade escolar forma, em um processo dialógico, o professor, a sua prática docente e, por conseguinte, as disciplinas escolares.

Nesse horizonte interpretativo, argumentamos que uma das formas de apreender e adentrar o universo escolar, é por meio da análise das práticas culturais que os objetos engendram. Segundo Souza (2013, p. 179-180), o objeto escolar "[...] pode ser um instrumento valioso para decifrar a cultura escolar à medida que as práticas são mediatizadas, em muitos sentidos, pelas condições materiais". Nesse sentido, nos alinhamos com Vinão Frago (1995) no entendimento de que a cultura escolar é, na realidade, tudo, abarcando, inclusive, a materialidade. Como aponta o autor, "[...] a cultura escolar é toda vida escolar: feitos e ideias, mentes e corpos, objetos e condutas, modos de pensar, dizer e fazer" (VINÃO FRAGO, 1995, p. 68-69, tradução nossa).

À luz dessas ponderações, os diferentes objetos que permeiam a disciplina escolar Biologia - animais taxidermizados, modelos didáticos, microscópios, lupas e etc. - ocupam um lugar central nos sentidos pelos quais a disciplina é concebida. Conforme destacado, os objetos podem fornecer indícios sobre as circunstâncias históricas nas quais eles foram utilizados, podendo ser percebidos como artefatos que "[...] ilustram, demonstram, apoiam, provocam, explicam, transformam, expressando indícios de concepções de educação e de ciência" (MARANDINO; SELLES; FERREIRA, 2009, p. 124).

Se, por um lado, o 'olhar' antropológico em relação aos objetos é importante para entendê-los aqui na interface com a cultura, por outro, a ação dos sujeitos é central para a compreensão da cultura escolar no âmbito da história da educação. Esta constatação, segundo Vidal (2006), apesar de parecer evidente, só foi fortalecida a partir dos anos 70. De receptáculos passivos de políticas mais amplas, professores e alunos passaram a "ser vistos como sujeitos privilegiados do processo de ensino-aprendizagem, pelas escolhas que efetuam e pelos saberes que produzem" (VIDAL, 2006, p. 36). Essa mudança de 'olhar' contribuiu para a modificação das pesquisas, seja a partir da elaboração e incorporação de outros arsenais teórico-metodológicos, seja pela ampliação dos objetos de pesquisa. Dessa forma, como aponta Vidal (2009, p. 36):

Investigar a prática docente, compreendendo-a na intersecção do saber e da ação de professores, instou a indagação sobre a mistura de vontades, gostos, experiências, acasos que foram consolidando gestos, rotinas, comportamentos identificados como docentes: o modo particular de organizar as aulas, de se movimentar na sala, de se dirigir aos alunos, de utilizar recursos didáticos e, mesmo, a maneira de organizar a relação pedagógica.

Esse conjunto de rituais e ações, caracterizados como docentes, podem ser percebidos a partir do conceito de "comunidades disciplinares" (GOODSON, 2013). Sob essa perspectiva, a comunidade representaria "[...] um movimento social incluindo uma gama variável de missões ou tradições distintas representadas por indivíduos, grupos, segmentos ou facções" (GOODSON, 1997, p. 44). Essa comunidade é heterogênea, ou seja, existem discursos que disputam entre si a hegemonia do bom ensino de Biologia. Os compartilhamentos de sentidos em torno da referida disciplina escolar são, na realidade, "[...] aqueles que venceram as disputas travadas e que se tornaram hegemônicos" (FERREIRA, 2005, p. 60). 
Apesar de existirem disputas e tensões, a comunidade disciplinar compartilha de objetivos comuns relacionados à ascensão da disciplina, "[...] conquistando os grupos legítimos com vista à obtenção de apoio ideológico e de recursos" (GOODSON, 1997, p. 44). Dessa forma, as comunidades disciplinares participam ativamente dos processos de permanências/transformações relacionados às disciplinas escolares. Contudo, esse papel ativo nos rumos das disciplinas escolares é limitado por fatores externos à comunidade escolar, como por exemplo, os sistemas educacionais que "promovem e sustentam determinadas visões sobre as disciplinas escolares" (FERREIRA, 2005, p. 21).

Segundo as contribuições de Goodson (1997, 2001, 2013), entendemos as disciplinas escolares e, com isso, a Biologia escolar, como constructos sócio-históricos que a partir de processos dinâmicos de estabilidade e mudança se constituem em torno de tradições e inovações. Há uma multiplicidade de tradições que identificam uma determinada cultura disciplinar, iniciando "o professor em visões amplamente diferentes sobre as hierarquias do conhecimento e sobre os conteúdos, o papel dos docentes e as orientações pedagógicas globais" (GOODSON, 2001, p. 174). De acordo com o autor, "[...] são estas tradições que actuam enquanto agência principal de iniciação dos professores nas comunidades disciplinares, pelo que são a face mais visível do fenómeno alargado da subcultura disciplinar" (GOODSON, 2001, p. 174).

Ao buscar definir tais tradições, inerentes a uma determinada cultura disciplinar, Goodson (2001) caracteriza a tradição acadêmica como associada a um conjunto de conhecimentos abstratos - de alto status - que são avaliados por exames; a tradição utilitária como aquela centrada no conhecimento prático cujos elementos predispõem o aluno ao exercício prático e técnico, associado ao mundo do trabalho; e a pedagógica, que compartilha de status baixo com o conhecimento prático e focaliza no "conhecimento pessoal, social e de senso comum" (GOODSON, 2001, p. 180).

Os objetos, como pertencentes às disciplinas escolares, estão imersos no processo sócio-histórico de construção das mesmas. A perspectiva de considerar "a elaboração de currículo" como "um processo pelo qual se inventa tradição" (GOODSON, 2013, p. 27) nos faz perceber que as inovações não deletam as tradições já existentes; pelo contrário, o novo dialoga com o antigo. Nesse sentido, concebemos os objetos nas aulas práticas do gabinete de História Natural como imersos na dinâmica de estruturação disciplinar uma vez que eles, a partir das práticas que engendram, podem também, no decorrer da história, estabelecer uma inovação que dialoga com outros objetos, e, consequentemente, com outras tradições, propiciando, igualmente, a criação de uma futura tradição.

Diante do exposto, este artigo encontra-se dividido nas seguintes seções principais: (i) a revisão do plano de ações educacionais tanto internacionais como nacionais que caracterizaram o movimento de renovação do ensino de Ciências; as discussões das reformas secundárias promulgadas nos anos 1960/1970; os entrelaçamentos históricos entre a disciplina escolar Biologia e as Ciências Biológicas; (ii) os aspectos metodológicos pelos quais a pesquisa foi delineada; (iii) as reflexões acerca dos resultados obtidos, buscando evidenciar o microscópio enquanto artefato escolar central na consolidação e inovação da Biologia escolar no Colégio Pedro II; e, (iv) as considerações finais acerca do papel do microscópio no plano da disciplina escolar Biologia da referida instituição. 


\section{As Contigências Históricas do Período 1950-1980}

Entre 1950 e 1980, no contexto da Guerra Fria, inúmeras iniciativas governamentais tiveram como foco inovar o ensino de Ciências a partir de uma metodologia experimental que marcou de modo significativo o ensino da Biologia (SELLES, 2008). As intervenções realizadas iniciaram-se de modo mais premente a partir do lançamento do satélite Sputnik, em 1957, pela União Soviética. Tal acontecimento a colocou no centro da corrida espacial no pós-segunda guerra mundial, desencadeando discussões nos países capitalistas no que tange ao seu desenvolvimento técnico-científico. Em decorrência disso, o ensino das Ciências foi questionado em termos qualitativos em reuniões patrocinadas por organizações internacionais, gerando uma série de feitos a fim de desenvolvê-lo como forma de superar a hegemonia do país socialista no plano tecnológico (BARRA; LORENZ, 1986; CHASSOT, 2004). Nessa esteira, países do bloco capitalista, como Inglaterra e Estados Unidos, organizaram centros e comitês de Ciências para produção de coleções didáticas e de projetos curriculares, unificando a proposta de combater a centralidade da União Soviética a partir do desenvolvimento do ensino das Ciências no contexto do bloco capitalista. Esses projetos também foram reformulados e apropriados por diversos países, incluindo o Brasil (BARRA; LORENZ, 1986; MARANDINO; SELLES; FERREIRA, 2009). Tais ações ficaram conhecidas pela égide do movimento de renovação do ensino de Ciências, cujo pilar central da experimentação seria a forma adequada de "[...] romper com práticas que atrelavam essa disciplina às tradições de memorização, passividade dos alunos e excesso de conteúdos desatualizados" (SELLES, 2008, p. 604).

No caso da Biologia escolar, esta se integrou ao movimento de renovação do ensino de Ciências "[...] por meio do projeto de reformulação curricular conhecido como "Biological Science Curriculum Study (BSCS)" (SELLES, 2008, p. 604). Esse projeto produziu uma série de materiais didáticos que foram traduzidos para diversos países, incluindo o Brasil. Tais materiais concretizaram o ideário da experimentação como a forma adequada de ensinar tal disciplina, buscando romper com o ensino tradicional, considerado defasado, com forte apelo à memorização e de caráter enciclopédico. Os livros do BSCS traziam esse discurso das práticas experimentais, diferenciando-se dos outros livros didáticos da época. Esse material também contribuiu para uma maior aproximação da disciplina escolar Biologia aos moldes da produção acadêmica, fortalecendo tanto a Biologia no contexto escolar como no âmbito universitário, colocando-a em uma posição de destaque a partir dos anos 1960 (FERREIRA; SELLES, 2008).

De acordo com Ferreira (2005), o ideário renovador promulgado pelo movimento de renovação do ensino de ciências encontrou terreno fértil no Brasil, visto que aqui já existia um movimento de renovação do ensino secundário que se coadunava com as suas proposições. As iniciativas de modernização do ensino secundário emergem no século XIX, acirrando-se entre as décadas de 1930 e 1970 do século XX, em torno da problemática entre um ensino baseado no humanismo clássico, desinteressado, historicamente voltado às elites; e um ensino de caráter científico e técnico (SOUZA, 2008, 2009). A predominância do currículo humanista durante o Império pode ser notada no Colégio Pedro II a partir de seus programas nos quais esses estudos eram enfatizados em detrimento das matérias científicas, como a Física e a Química (MASSUNAGA, 1989 apud FERREIRA, 2005).

Após anos de debates em torno das finalidades educacionais para o ensino secundário, a Lei de Diretrizes e Bases de 1961 inicia uma "[...] ruptura dos padrões de composição e 
ordenação curricular prevalecentes no ensino secundário brasileiro" (SOUZA, 2008, p. 154). Para alguns autores (BARRA; LORENZ, 1986; CHASSOT, 2004), essa reforma trouxe para o Brasil um movimento de valorização dos estudos científicos, propiciando que as perspectivas do movimento de renovação do ensino de Ciências adentrassem os 'muros' da escola. Essa legislação permitiu, inclusive, a adoção de materiais didáticos que materializavam os ideais desse movimento em torno de metodologias experimentais, aproximando as finalidades escolares das acadêmicas.

\section{Inter-relações entre Biologia Escolar e Ciências Biológicas}

O processo de compreensão da história da constituição da disciplina escolar Biologia perpassa pelo conhecimento do percurso histórico da estruturação de seu campo de referência, as Ciências Biológicas. A Biologia escolar parece ter promulgado um ideal de uma disciplina una e modernizada, contribuindo para um apagamento de embates e entraves que se travaram na esfera do estabelecimento de sua disciplina de referência. As Ciências Biológicas, no interior de sua comunidade disciplinar, especialmente entre os anos 1930 e 1950, enfrentaram uma série de batalhas antes de se tornar uma ciência unificada, como a Física e a Química, que já tinham alcançado o estatuto de ciência desde o século XVIII (MARANDINO; SELLES; FERREIRA, 2009).

Os vários eixos de conhecimentos, identificados com distintas tradições epistemológicas, que compõem hoje o que conhecemos sob a designação de Ciências Biológicas, no início do século XX, estavam segregados em ramos distintos de caráter naturalista, influenciados pela História Natural, como a Zoologia e a Botânica; e outros que se identificavam com a prática experimental como a Citologia, a Embriologia e, particularmente, a Fisiologia Humana (FERREIRA; SELLES, 2008; MARANDINO; SELLES; FERREIRA, 2009; SELLES; FERREIRA, 2005). A segmentação desse campo científico "[...] reforçava o menor status dos referidos conhecimentos face às ciências mais consolidadas, especialmente a Física" (FERREIRA; SELLES, 2008, p. 45).

As Ciências Biológicas só puderam atingir o patamar de ciência autônoma e unificada após a teoria da evolução, elaborada por Charles Darwin em 1859, ter sido formulada. A emergência da Genética, atrelada às influências do paradigma positivista, contribuiu para o empreendimento de congregar distintas tradições sob a mesma ciência a partir da reformulação dos estudos evolutivos (FERREIRA, 2005; FERREIRA; SELLES, 2008; MARANDINO; SELLES; FERREIRA, 2009). O processo de unificação das Ciências Biológicas iniciou-se com a ressignificação da teoria da evolução a partir de pressupostos genético-mendelianos, sendo, posteriormente, consolidados tanto pelas formulações da genética de populações como pelo advento da Genética Molecular, pois ambas traziam para o âmbito das Ciências Biológicas um caráter positivista e quantitativo. Ainda que tenham existido desencontros referentes às diferentes perspectivas pelos quais as diferentes áreas no interior da Biologia produzem conhecimento, como a Genética Molecular e a Zoologia, "[...] podemos afirmar com certeza que, hoje, todas as áreas do conhecimento das Ciências Biológicas aceitam a Evolução" (MARANDINO; SELLES; FERREIRA, 2009, p. 46).

Da mesma maneira que a Evolução foi o 'fio' condutor que contribuiu para a consolidação das Ciências Biológicas, fortalecendo-a enquanto ciência única, 
[...] a gradativa substituição de disciplinas escolares como Zoologia, Botânica e História Natural pela disciplina escolar Biologia fortaleceu o argumento de que a evolução funcionasse, igualmente, como organizadora dos conhecimentos escolares em Biologia. (SELLES; FERREIRA, 2005, p. 54).

Isso pode ser visualizado nos materiais BSCS que contribuíram para a promulgação de uma retórica unificadora e moderna das Ciências Biológicas tanto por meio da ênfase em um caráter experimental quanto pela disseminação da Evolução como agregadora dos diferentes ramos dessa ciência.

\section{Aspectos Metodológicos}

O processo de entender a circunscrição de práticas escolares no gabinete de História Natural a partir da materialidade que compõe a disciplina escolar Biologia foi realizado com base em: entrevistas semiestruturadas; documentos oficiais do Colégio Pedro II; legislações vigentes no referido período; um livro de registro de aulas práticas de laboratório do referido gabinete; e as teses de Ferreira (2005) e Cassab (2011), que serviram de fontes secundárias.

A opção de conjugar fontes diversas é devida ao fato de podermos alargar o escopo empírico de forma a compreender a gestão de práticas, pois estas "[...] produzem-se como um ato, como uma operação, o que nem sempre lhes permite legar registros à história" (VIDAL, 2006, p. 158). Assim, entrevistamos três ex-professores ${ }^{2}$ do referido estabelecimento escolar a fim de nos acercarmos mais detidamente das práticas escolares pretéritas, buscando responder indagações que emergiram no decorrer do processo de análise das fontes escritas. A utilização de entrevistas concorreu para o alargamento do escopo de conhecimentos acerca das práticas escolares gestadas no interior do laboratório de História Natural, permitindo "[...] aumentar a compreensão desses fazeres com, das rotinas escolares e da constituição de corporeidades nos sujeitos na escola" (VIDAL, 2006, p. 161).

No que tange ao conjunto do material empírico, este foi produzido de acordo com as resoluções éticas brasileiras. Como a investigação envolveu a participação de ex-professores do Colégio Pedro II, foi preciso submeter o projeto de dissertação ao Comitê de Ética em Pesquisa do Centro de Filosofia e Ciências Humanas (CFCH) da UFRJ. Após a aprovação, iniciamos o processo de produção das entrevistas. Em acordo com os parâmetros de ética vigentes no referido comitê, a identidade dos professores foi tratada a partir de padrões profissionais de sigilo no qual as informações obtidas foram utilizadas somente para os fins acadêmicos da presente investigação. Sob esse aspecto, os professores entrevistados foram designados pelas letras A, B e C. O armazenamento dos dados produzidos a partir das entrevistas encontra-se disponibilizado no acervo do Grupo de estudos Currículos escolares, ensino de Ciências e materiais didáticos, pertencente ao Laboratório do Núcleo de Estudos de Currículo (NEC) da Universidade Federal do Rio de Janeiro (UFRJ).

Em conjunto com esses dados analisamos um livro de registro de aulas práticas de laboratório realizadas no gabinete de História Natural nos anos de 1970. Do ponto de vista do contexto histórico de sua produção e utilização, o referido livro abarca o período entre 09/11/1972 a 18/11/1975. Esse material é uma espécie de caderno de atas de capa dura preta, pautado e com linhas. Cada folha é numerada, totalizando 358 páginas de registro.

\footnotetext{
${ }^{2} \mathrm{~A}$ escolha de profissionais atendeu a um pré-requisito: ter lecionado aulas práticas no laboratório do gabinete de História Natural nos anos 1960/1970 na unidade Centro do Colégio Pedro II.
} 
Cabe mencionar que o livro foi redigido por uma profissional que, segundo o Anuário do Colégio Pedro II (Volume XVI/ 1951-1961, Rio de Janeiro: Imprensa Nacional, 1963), era zeladora da referida escola. Contudo, conforme consta no depoimento prestado pela professora A e no livro de registro, a referida funcionária auxiliava o trabalho docente no que tange às aulas práticas ministradas no gabinete de História Natural.

É importante frisar que esse livro de registro é analisado aqui a partir de duas perspectivas: uma, advinda do campo dos estudos curriculares, em especial das contribuições de Ivor Goodson e de autores que dele têm se apropriado como referência teórica, em que os documentos são percebidos como um "[...] testemunho público e visível dos conflitos que envolvem as decisões e ações curriculares" (FERREIRA, 2005); e outra, associada aos estudos acerca da materialidade enquanto parte integrante da cultura escolar que nos permite perceber o livro como um "resto arqueológico" (ESCOLANO BENITO, 2010) que nos informa sobre práticas, valores, tradições, nos permitindo adentrar a "caixa preta" escolar e seus fazeres internos. Em outras palavras, tal material empírico é um vestígio; um testemunho de como eram gestadas as aulas práticas no gabinete de História Natural, nos auxiliando na compreensão de como os objetos eram mobilizados nas atividades.

Nessa esteira, apropriado em sua materialidade, tal objeto permite tanto "[...] a percepção dos conteúdos ensinados, a partir de uma análise dos enunciados e das respostas" como "[...] o entendimento do conjunto de fazeres ativados no interior da escola" (VIDAL, 2006, p. 160). Portanto, a fim de nos acercarmos das práticas culturais postas em ação pela relação dialógica entre os artefatos e os docentes, buscamos, primeiramente, entender a associação dos materiais didáticos com os conteúdos e áreas disciplinares da Biologia, tentando mergulhar nos sentidos que a materialidade escolar fabrica no âmbito do fazer escolar. Sendo assim, procuramos associar cada aula prática a um dos eixos das Ciências Biológicas, isto é, ora como mais pertinente à História Natural, como a Zoologia e a Botânica; ora como mais inter-relacionada ao processo de modernização das Ciências Biológicas, como a Genética e a Citologia, por exemplo (MARANDINO; SELLES; FERREIRA, 2009).

Quadro 1 - Descrição das áreas consideradas na investigação

\begin{tabular}{|c|c|}
\hline Área & Descrição \\
\hline $\begin{array}{l}\text { Anatomia e Fisiologia } \\
\text { Humana }\end{array}$ & $\begin{array}{l}\text { Práticas relacionadas com a Anatomia ou Fisiologia Humana e que apresentam traços relativos à Bioquí- } \\
\text { mica. Por exemplo, pesquisa de glicose na urina. }\end{array}$ \\
\hline Bioquímica & $\begin{array}{l}\text { Propriedades químicas de moléculas e substâncias; experimentos para identificação de substâncias diversas; } \\
\text { práticas de quantificação de substânicas; processos bioquímicos, como a fermentação. }\end{array}$ \\
\hline Botânica & $\begin{array}{l}\text { Teoria sobre fungos e observação macroscópicas de folhas; descrição de estruturas, como cor, forma e } \\
\text { disposição das folhas; caule; nervuras; limbo; e superfícies inferior e superior. }\end{array}$ \\
\hline Citologia & $\begin{array}{l}\text { Estudo da célula e observação microscópica de células animais e vegetais, incluindo, de seres microscópicos, } \\
\text { como protozoários; práticas relativas ao transporte de substâncias pela célula, como osmose e difusão. }\end{array}$ \\
\hline Física e Química & Práticas relativas ao movimento browniano e à densidade. \\
\hline Genética & Determinação dos grupos sanguíneos; conceitos e noções de genética. \\
\hline Histologia & Práticas relacionadas à identificação de células sanguíneas a partir do esfregaço de sangue. \\
\hline Microbiologia & Estudo das bactérias e dos métodos de esterilização. \\
\hline Microscopia & $\begin{array}{l}\text { Práticas relacionadas ao uso do microscópio, incluindo as finalidades de cada componente do referido } \\
\text { objeto; focalização e poder de resolução do microscópio. }\end{array}$ \\
\hline Química & $\begin{array}{l}\text { Práticas relacionadas aos processos de filtração, purificação, precipitação, decantação, dissolução; técnica } \\
\text { de aquecimento de líquidos, misturas, dispersões, soluções e solubilidade. }\end{array}$ \\
\hline Zoologia & $\begin{array}{l}\text { Dissecção de animais; estudo da anatomia e fisiologia de animais; classificação dos protozoários, incluindo } \\
\text { o estudo de tipos patogênicos. }\end{array}$ \\
\hline
\end{tabular}

Fonte: Oliveira (2018). 
As atividades mencionadas no referido livro de registro foram analisadas e categorizadas. As atividades práticas ali citadas foram, portanto, classificadas como pertencentes a cada um dos seguintes eixos: Anatomia e Fisiologia Humana; Bioquímica; Botânica; Citologia; Física e Química; Genética; Histologia; Microbiologia; Química; e, Zoologia. Cabe destacar que as primeiras aulas dos anos letivos não puderam ser associadas a nenhum dos ramos mencionados, pois eram atividades de ordem no laboratório e/ou procedimentos laboratoriais que foram categorizadas sob a denominação de 'laboratório'3. No Quadro 1 detalhamos como foi o processo de categorização e o que consideramos como relacionado a determinado campo de especialidade.

No intuito de mensurar a relevância relativa, em porcentagem, de cada um dos ramos apresentados anteriormente, quantificamos o número de aulas referentes a determinado eixo e dividimos pela quantidade de atividades totais ministradas no ano letivo correspondente. Buscamos também mensurar a frequência relativa em que determinado objeto apareceu nas atividades registradas no livro de aulas práticas. O procedimento de ambas as análises foi realizado por blocos correspondentes aos anos letivos, como os indicados no Quadro 2.

Quadro 2 - Número de aulas do ano letivo por período de atividade

\begin{tabular}{|l|l|l|}
\hline \multicolumn{1}{|c|}{ Bloco } & \multicolumn{1}{|c|}{ Período de atividade } & \multicolumn{1}{c|}{ Número de aulas do ano letivo } \\
\hline 1 & $09 / 11 / 1972$ a $14 / 11 / 1972$ & Não foi possível contabilizar; No livro de registro há referência apenas a 4 aulas \\
\hline 2 & $20 / 03 / 1973$ a $13 / 11 / 1973$ & 177 aulas \\
\hline 3 & $20 / 03 / 1974$ a $25 / 09 / 1974$ & 115 aulas \\
\hline 4 & $13 / 05 / 1975$ a $18 / 11 / 1975$ & 41 aulas \\
\hline
\end{tabular}

Fonte: Oliveira (2018).

\section{O Microscópio e o Ensino de Biologia no Colégio Pedro II}

A compreensão da história do microscópio na esfera de unificação e constituição da Ciências Biológicas é essencial para entendermos a importância do mesmo no contexto escolar. Segundo Valério e Torresan (2017, p. 128), tal objeto, gestado no âmbito de uma "ciência experimental renascentista, aju daria a reconstruir [...] o ideal de observação científica das Ciências Biológicas, e a faria despertar de um 'sono profundo' para torná-la uma ciência imprescindível na explicação do mundo". Com o desenvolvimento e o aperfeiçoamento da microscopia, entre o século XVII e XVIII, o espectro de conhecimentos biológicos se abriram para um novo universo de seres microscópicos até então nunca imaginados. Em conjunto com as teorias evolutivas e celulares, a microscopia também permitiu que novas frentes de conhecimentos fossem gestadas, garantindo a unificação dessas ciências, e, colocando-as no mesmo patamar de prestígio das ciências ditas hard, como a Física (VALÉRIO; TORRESAN, 2017).

Se o microscópio, e o seu subsequente ramo de estudos, a microscopia, tiveram um papel fundamental na validação das Ciências Biológicas enquanto um campo legítimo, aquele também parece ter sido muito importante nas aulas práticas de Biologia no Colégio Pedro II. Na análise empírica, verificamos um papel de centralidade atribuído ao microscópio no delineamento da cultura disciplinar do ensino de Biologia, pois este foi o artefato mais utilizado em todos os anos letivos. Em 1973, o microscópio encontra-se presente em 97 
atividades práticas, isto é, em 54,80\% das aulas; em 1974, este é enunciado em 47 aulas, ou seja, em 40,96\% das aulas ministradas no período; e em 18 aulas em 1975, correspondendo a $43,90 \%$ das aulas lecionadas. Isso ainda pode ser verificado nos depoimentos a seguir:

Quais eram os objetos escolares mais utilizados em suas aulas? [Pesquisadora].

O microscópio. O objeto? Era o microscópio. [Professora A].

O microscópio estava sempre? [Pesquisadora].

Sempre. Você chegava e já tinha um microscópio na mesa. [Professora A].

Interrogada sobre quais objetos escolares a professora C não poderia "abrir mão", ela também responde que o microscópio é essencial na materialização das atividades práticas, especialmente aquelas relacionadas aos experimentos:

Eu acho assim, objeto específico, eu acho que esse material óptico, como eu já falei. Eu acho que você não podia abrir mão porque como você vai fazer trabalhos de célula, de tudo aquilo que você não pode ver a olho nu, se você não tiver com o material óptico específico para você fazer os experimentos? Você não pode abrir mão porque daí você vai dizer: como é que eu vou dar aula dessa forma? Como é que eu vou fazer o experimento, se eu não tenho material óptico? Eu acho que o material óptico na época que a gente tinha, que eram bons para época, eu acho que a gente não podia abrir mão porque sem eles a gente não podia realmente fazer tudo aquilo que a gente gostaria de trabalhar com os alunos. Então, eu acho que isso era uma das coisas que a gente não podia abrir mão. [Professora C]

Em acordo com Valério e Torresan (2017, p. 130), "[...] toda organização das áreas de conhecimentos biológicos recebera influência, direta ou indireta, do advento e refinamento do microscópio e de seus resultados". Essa posição de destaque na estruturação do pensamento biológico também pode ser verificada no depoimento do professor $\mathrm{B}$, a seguir, que demarca o caráter de relevância do microscópio na Biologia escolar:

O papel dele é fundamental, né? Porque se você, por exemplo, vai observar uma célula sanguínea, você vê o sangue, você vê o plasma. Mas agora vê o que está ali dentro você não vai ver, só vai ver com o auxílio do aparelho. Não é verdade? Então, essa era a coisa mais importante. Não só da Biologia em si como um todo, mas também dentro da Biologia, dentro da genética e dentro de outras áreas dentro da Biologia, dos próprios seres vivos de uma maneira geral, né? Uma cultura, por exemplo, de bactérias. [Professor B].

O estudo da microscopia e de seu respectivo objeto também integrava um conjunto de práticas que eram empreendidas no gabinete de História Natural do Colégio Pedro II. Em tais atividades, os alunos aprendiam sobre suas partes componentes (ótica e mecânica) e também sobre os seus respectivos mecanismos de movimentos. Como essas aulas eram lecionadas no início do ano letivo, induzimos que elas serviam para inserir e familiarizar os estudantes na cultura disciplinar da Biologia no que tange ao manuseio correto do microscópio. Assim, por exemplo, na aula do dia 23/03/1973, encontramos uma definição de microscópio como sendo "um instrumento que permite observar os objetos não perceptíveis à vista desarmada" e que é formado por "um sistema óptico composto por lentes de cristal que atravessadas pela imagem do objeto, ampliam-na". Verificamos, portanto, que o microscópio no âmbito dessas atividades práticas é relacionado a termos técnicos, sendo correlacionado a condutas científicas de utilização deste objeto, aproximando essas aulas às finalidades de natureza técnica e acadêmica. Desse modo: 
A introdução dos estudantes em procedimentos 'quase' científicos - como a preparação de lâminas e o desenvolvimento de habilidades de observação - tornase não apenas a instauração de representações simbólicas no contexto didático, mas também uma aproximação do contexto científico que dá concretude aos processos de ensinar e aprender (MARANDINO; SELLES; FERREIRA, 2009, p. 105).

Compartilhamos, ainda, com Selles (2008 p. 598) que " [...] os lugares (e os tempos) em que se dão os processos de ensinar e aprender as práticas experimentais nessa disciplina são atravessados por uma seleção de elementos da cultura científica, os quais são recriados e ressignificados na cultura escolar."

Em outras palavras, os objetos utilizados nas aulas práticas de Biologia, 'guardam' referências com o conhecimento científico, produzido na academia, porém, ao serem introduzidos no ambiente escolar, 'escolarizam' as práticas científicas, produzindo conhecimentos que ora correlacionam-se com 'tradições' acadêmicas, ora com 'tradições' pedagógicas e utilitárias. Nesse sentido, o trecho a seguir demonstra tal argumento uma vez que a utilização do microscópio dialoga com o mundo cotidiano do aluno, estabelecendo relações com este.

Não é só ficar olhando no microscópio. É ligar com o mundo real, entendeu? Eles entenderem como é que as coisas funcionam na natureza, na vida. Não é chegar ali e olhar, olhar uma figura em mitose, sim e daí? Agora no seu corpo onde é que está acontecendo isso que está aqui? [Professora A].

O microscópio também materializou os sentidos desse ensino experimental, alinhando-se ao movimento renovador do ensino de Ciências, ao mesmo tempo em que o consolidava na referida instituição. Apesar do microscópio ter redirecionado o rumo da disciplina Biologia, introduzindo novos elementos ao seu fazer disciplinar, este também conversou com tradições já consolidadas no âmbito da disciplina, ou seja, com as práticas de dissecção e observação de animais, ou nos termos da entrevistada a seguir, com a velharia:

Nas aulas práticas, nós erámos considerados já muito, muito modernos. Porque nós fazíamos coisas que hoje são ridículas, né? Hoje se faz... O que nós fazíamos, hoje se faz na oitava, na quinta série. Que eram experimentos de pegar as células, olhar, olhar no microscópio, corar e distinguir o que é o núcleo, o que é a mitocôndria. Na época era avançado, já era um enfoque mais contemporâneo. Mas, além disso, os alunos também tinham a velharia. [Professora A].

É válido ressaltar que não estamos afirmando que o microscópio não existia anteriormente aos anos 1960/1970 nas aulas práticas da disciplina. O que queremos ressaltar é que, no âmbito da sua trajetória histórica, esse artefato se alinhou com o movimento de renovação do ensino de Ciências, permitindo que as práticas experimentais fossem associadas ao bom ensino de Biologia, contribuindo para a construção de uma noção de ensino inovada. Não podemos afirmar se antes do recorte temporal do presente trabalho havia esse tipo de prática associada a esse objeto. Não podemos inferir isso, mas assim como os BSCS assumiram um papel de "agente renovador" (SELLES, 2008), os microscópios também podem ser visualizados como artefatos que trazem e consolidam esse sentido de renovação para o ensino da Biologia escolar.

Evidenciamos que este artefato também congregou os diferentes ramos biológicos no âmbito das aulas práticas no referido gabinete, pois o mesmo é mobilizado em todas as atividades mencionadas a seguir. No ano de 1973, as áreas de maior destaque foram a 
Citologia (30,79\%), a Zoologia (19,77\%) e a Bioquímica (15,25\%). As três áreas somam mais de metade das atividades desse ano letivo, representando 65,81\%. No ano letivo de 1974 , as áreas de maior representatividade foram a Citologia (24,56\%), a Zoologia (22,60\%) e a Bioquímica $(15,21 \%)$, contabilizando $62,37 \%$. Já no ano de 1975 , as áreas de maior relevância foram Anatomia e Fisiologia Humana (39,02\%); e Citologia (24,4\%), totalizando $63,42 \%$. Cabe destacar que o microscópio apareceu em uma área especificamente para seu estudo, qual seja, a microscopia no âmbito das atividades práticas de 1973 (8,75\%) e 1974 $(4,34 \%)$.

Com base nesses dados, afirmamos que se a Evolução foi o fio condutor que permitiu a consolidação e unificação das Ciências Biológicas, sustentando-a como ciência única e legítima, fortalecendo e organizando, inclusive, os conhecimentos escolares no Ensino de Biologia (MARANDINO; SELLES; FERREIRA, 2009), no plano do ensino de Biologia no Colégio Pedro II foi o microscópio que assumiu essa função de sustentar e congregar os diferentes ramos biológicos, garantindo a modernização da disciplina em questão. Embora a evolução tenha sustentado a unificação das Ciências Biológicas (MARANDINO; SELLES; FERREIRA, 2009), na dimensão das atividades práticas é o microscópio que parecia garantir e dar a base, disseminando uma Biologia tanto unificada quanto moderna, possibilitando, inclusive, a realização de experimentos. Dessa forma, a consolidação da Biologia escolar, e o respectivo processo de conformação dessa disciplina frente à História Natural, parece estar associada, no âmbito das aulas práticas realizadas no gabinete, à mobilização do microscópio tanto nos ramos que trouxeram uma ideia de modernização para as Ciências Biológicas, como a Citologia, quanto nas áreas de tradições naturalistas, especialmente nas atividades de dissecção de animais, classificadas como pertencentes à Zoologia. Essa utilização do microscópio em ambas as áreas pode ser identificada pelo trecho da entrevista abaixo:

Todas as aulas tinham um microscópio, tinha... eventualmente, a aula não era de microscópio, né? Quando tinha uma dissecção. Acho que até dissecção tinha microscópio porque nós abríamos o intestino para pegar fezes, para olhar bactérias, para olhar protozoários. Sempre quando entrava na sala de aula tinha um kit para cada aluno, uma bandeja, um microscópio, a vidraria, os reagentes e o roteiro do lado. [Professora A].

Ademais, o microscópio pode ser visto naquele momento como essencial na materialização das atividades práticas, associando o bom professor com aquele que concretiza o ensino prático, não se restringindo apenas à teoria. Conforme aponta Lucas (2014, p. 75, grifo do autor),

[...] o caráter prático dessa formação, "mesclando" tradições da História Natural com técnicas estatísticas e do mundo microscópico, tem sido visto, historicamente, como um modo de combater a usual dicotomia entre teoria e prática e formar um "bom" professor nessa área.

A partir dos depoimentos dos ex-professores, percebemos que o microscópio é um dos principais objetos que viabilizam o ensino prático da Biologia escolar no Colégio Pedro Il durante o período analisado.

Se como afirmam Valério e Torresan (2017, p. 133), "a história da Biologia corresponde em maior ou menor grau, à história dos resultados das melhorias técnicas", a referida disciplina na escola também é impactada pelo aperfeiçoamento e introdução dos a parelhos no contexto escolar. Acreditamos que no decorrer da trajetória histórica desse objeto, ele propiciou, 
no período investigado, novas conformações para o ensino de Biologia, consolidando o movimento renovador do ensino de Ciências na referida instituição, mantendo as práticas identificadas como sendo da História Natural. Tomando as palavras de Valério e Torresan (2017, p. 133, grifo dos autores):

Como uma "metáfora ecológica", o microscópio provocou no pensamento biológico o mesmo que uma nova espécie provoca quando alocada em um ecossistema estabelecido; nada é subtraído ou adicionado, mas tudo é profundamente mudado pela chegada da novidade.

\section{Considerações Finais}

No decorrer dos anos 1960, a disciplina escolar Biologia, influenciada tanto pelas reformas educacionais brasileiras, como por concepções inovadoras, advindas do movimento renovador do ensino de Ciências, viu-se imersa em meio "[...] a discursos pedagógicos alimentados pelo ideário inovador [que] elevaram a experimentação na disciplina escolar Biologia a uma metodologia didática plenamente identificada com a ciência de referência" (SELLES, 2008, p. 603), isto é, com as Ciências Biológicas. Como apontado pelos docentes, a mobilização dos microscópios nas aulas práticas era considerada como uma prática moderna, e, dessa maneira, consolidava a experimentação no ensino de Biologia no Colégio Pedro II. Além disso, as atividades desenvolvidas no gabinete de História Natural também permitiram a participação ativa dos alunos, permitindo que os mesmos vivenciassem o método científico, orientador das Ciências Biológicas.

Ao analisarmos os objetos escolares mais utilizados na disciplina escolar Biologia, percebemos que o microscópio pode ser considerado como central, presente tanto na análise dos dados registrados no livro de registro de aulas práticas como nos depoimentos dos ex-professores. Tal objeto esteve presente nas áreas de maior representatividade nos anos letivos. $E$, assim, argumentamos que, além de ter garantido a consolidação das Ciências Biológicas, esse artefato também permitiu uma aproximação do fazer do ensino de Biologia com esse campo de estudos, marcando as práticas a partir de tradições, predominantemente, acadêmicas. No processo de transição da História Natural para a Biologia escolar no Colégio Pedro II, o microscópio teve um papel central nesse movimento, garantindo tanto a unificação entre os diferentes ramos da Biologia na dimensão do ensino prático como também a legitimação e o status dessa disciplina.

Considerado em sua materialidade, o microscópio produz sentidos curriculares que nos permitem percebê-lo no feixe de relações que conforma a cultura disciplinar do Ensino de Biologia e a sua comunidade disciplinar. Compreendendo os objetos escolares enquanto instrumentos que expressam as tradições e o ensino em voga (ESCOLANO BENITO, 2010), entendemos aqui o microscópio no gabinete de História Natural como formador da cultura disciplinar, iniciando os professores no modus operandi do fazer da Biologia escolar. Imersos no processo de constituição da cultura escolar, tal material didático é percebido como um agente ativo no processo de modulação, formulação e invenção da disciplina escolar Biologia no Colégio Pedro II.

Se a história do microscópio demonstra uma mudança na conformação da Biologia como ciência, podemos pensar que o mesmo também exerceu seu papel no processo de inovação das práticas da Biologia escolar na referida instituição. A partir desse prisma, argumentamos que se a evolução foi o fio condutor no processo de consolidação e unificação 
das Ciências Biológicas, sendo essa retórica também apropriada pela escola, foi o microscópio que garantiu essa consolidação e organização da Biologia no âmbito do ensino prático no Colégio Pedro II. Portanto, argumentamos que o microscópio dá a base para a transição da História Natural para Biologia no contexto da instituição. Logo, esse artefato contribuiu para o processo de modernização do ensino dessa matéria escolar. No contexto de sua trajetória histórica, ressaltamos que tal objeto se alinhou tanto com o movimento de renovação do ensino de ciências como com a reforma do ensino secundário brasileiro, contribuindo para uma noção de ensino inovada e moderna.

Ademais, ao participarem dos processos de produção de normas e sentidos sobre os quais os conteúdos dessa matéria são administrados, os microscópios também inventam tradições que se correlacionam, predominantemente, com os rituais científicos, mas que no contato dialógico com os docentes, proporcionavam também a produção de tradições de cunho pedagógico, relacionados ao cotidiano dos alunos.

O microscópio identifica a comunidade disciplinar da Biologia escolar em torno de rituais que são partilhados pela mesma, marcando também tradições pedagógicas referentes ao bom ensino de Biologia. Parece pertinente argumentar, então, que o microscópio forma os docentes, organizando uma cultura disciplinar da Biologia e constituindo uma cultura profissional docente em torno de práticas "artesanais" de ofício, transmitidas mediante "rituais" vigentes na corporação docente (ESCOLANO BENITO, 2010), ou, nas palavras de Goodson (1997), pela comunidade disciplinar.

\section{Agradecimentos}

O presente trabalho é parte de uma Dissertação de Mestrado, defendida no Programa de Pós-graduação em Educação da Universidade Federal do Rio de Janeiro (UFRJ), que foi realizada com o apoio da Coordenação de Pessoal de Nível Superior (CAPES), Código de Financiamento 001.

Agradecemos ao Núcleo de Documentação e Memória (NUDOM) do Colégio Pedro II por ter possibilitado o acesso ao seu acervo.

\section{Referências}

BARRA, V. M.; LORENZ, K. M. Produção de materiais didáticos de ciências no Brasil, período: 1950 a 1980. Ciência e Cultura, Campinas, v. 38, n. 12, p.1970-1983, 1986.

CASSAB, M. A emergência da disciplina escolar biologia (1961-1981): renovação e tradição. 2011. 238 f. Tese (Doutorado em Educação) - Faculdade de Educação, Universidade Federal Fluminense, Niterói, 2011.

CHASSOT, A. Ensino de ciências no começo da segunda metade do século da tecnologia. In: LOPES, A.; MACEDO, E. (org.). Currículo de ciências em debate. Campinas: Papirus, 2004. p. 13-44.

ESCOLANO BENITO, A. La cultura material de la escuela y la educación patrimonial. Educatio Siglo XXI, Murcia, v. 28, n. 2, p. 43-64, 2010. Disponível em: https://revistas.um.es/educatio/article/ view/111961. Acesso em: 7 out. 2020.

FERREIRA, M. S. A história da disciplina escolar ciências no Colégio Pedro II (1960-1980). 2005. 212 f. Tese (Doutorado em Educação) - Faculdade de Educação, Universidade Federal do Rio de Janeiro, Rio de Janeiro, 2005. 
FERREIRA, M. S.; SELLES, S. E. Entrelaçamentos históricos das ciências biológicas com a disciplina escolar biologia: investigando a versão azul do BSCS. In: PEREIRA, M. G.; AMORIM, A. C. R. Ensino de biologia: fios e desafios na construção de saberes. João Pessoa: UFPB, 2008. p. 37-61.

FISCARELLI, R. B. O. A construção do saber sobre a utilização de objetos no ensino brasileiro. 2009. 171 f. Tese (Doutorado em Educação Escolar) - Universidade Estadual Paulista, Araraquara, 2009. Disponível em: http://hdl.handle.net/11449/101540. Acesso em: 7 out. 2020.

GONÇALVES, J. R. S. Antropologia dos objetos: coleções, museus e patrimônios. Rio de Janeiro: Ministério da Cultura: Departamento de Museus e Centros Culturais, 2007.

GOODSON, I. F. A construção social do currículo. Lisboa: EDUCA, 1997.

GOODSON, I. F. O currículo em mudança. Porto: Porto Editora, 2001.

GOODSON, I. F. Currículo: teoria e história. Petrópolis: Vozes, 2013.

LUCAS, M. C. Formação de professores de ciências e biologia nas décadas de 1960/70: entre tradições e inovações curriculares. 2014. 128 f. Dissertação (Mestrado em Educação) - Faculdade de Educação, Universidade Federal do Rio de Janeiro, Rio de Janeiro, 2014.

MARANDINO, M.; SELLES, S. E.; FERREIRA, M. S. Ensino de biologia: histórias e práticas em diferentes espaços educativos. São Paulo: Cortez, 2009.

MILLER, D. Trecos, troços e coisas: estudos antropológicos sobre cultura material. Rio de Janeiro: Zahar, 2013.

OLIVEIRA, F. A. Objetos escolares no ensino de biologia: entre práticas e tradições no gabinete de história natural do Colégio Pedro II (1960-1970). 2018. 134 f. Dissertação (Mestrado em Educação) - Faculdade de Educação, Universidade Federal do Rio de Janeiro, Rio de Janeiro, 2018.

SELLES, S. E. Lugares e culturas na disciplina escolar biologia: examinando as práticas experimentais nos processos de ensinar e aprender. In: TRAVERSINI, C.; EGGERT, E.; PERES, E. E.; BONIN, I. Trajetórias e processos de ensinar e aprender: práticas e didáticas. Porto Alegre: EdiPUCRS, 2008. p. 592-617.

SELLES, S. E.; FERREIRA, M. S. Disciplina escolar biologia: entre a retórica unificadora e as questões sociais. In: AMORIM, A. C. R.; SELLES, S. E.; MARANDINO, M.; FERREIRA, M. S. (org.). Ensino de biologia: conhecimentos e valores em disputa. Niterói: EDUFF, 2005. p. 50-62.

SOUZA, R. F. A renovação didática da escola secundária brasileira nos anos 60 . Linguagens, Educação e Sociedade, Teresina, ano 13, n. 18, p. 142-156, 2008.

SOUZA, R. F. Objetos de ensino: a renovação pedagógica e material da escola primária no Brasil, no século XX. Educar em Revista, Curitiba, n. 49, p. 103-120, 2013. DOI: https://doi.org/fck3.

VALÉRIO, M.; TORRESAN, C. A invenção do microscópio e o despertar do pensamento biológico: um ensaio sobre as marcas da tecnologia no desenvolvimento das ciências da vida. REnBio: revista de ensino de biologia da SBEnBio, Feira de Santana, v. 10, n.1, p. 125-134, 2017.

VIDAL, D. G. Cultura e práticas escolares: a escola pública brasileira como objeto de pesquisa. Historia de la Educación, Salamanca, n. 25, p. 153-171, 2006.

VIDAL, D. G. No interior da sala de aula: ensaio sobre cultura e práticas escolares. Currículo sem Fronteiras, Brasil, v. 9, n. 1, p. 25-41, 2009.

VIÑAO FRAGO, A. Historia de la educación y historia cultural: posibilidades, problemas, cuestiones. Revista Brasileira de Educação, Rio de Janeiro, n. 0, p. 63-82, set./dez. 1995. Disponível em: https:// cutt.ly/RgoCfce. Acesso em: 10 out. 2020. 